\title{
ANTIMICROBIAL ACTIVITY OF STREPTOMYCES VARIABILIS STRAIN-VITUMVBO3 ISOLATED FROM KANYAKUMARI MARINE SEDIMENTS
}

\author{
SHUBHA M, USHASHI B, VEENA S, BHASKARA RAO KV*
}

Department of Biomedical Sciences, Molecular and Microbiology Research Laboratory, School of Bio Sciences and Technology, VIT University, Vellore - 632 014, Tamil Nadu, India. Email: kokatibhaskar@yahoo.co.in

Received: 18 April 2017, Revised and Accepted: 20 May 2017

\section{ABSTRACT}

Objective: This study was focused on an evaluation of antimicrobial activity of actinobacteria isolated from Kanyakumari marine sediments.

Methods: This study includes sample collection from Kanyakumari beach, followed by isolation of marine Actinobacteria, screening for antibacterial activity and antifungal activity. Finally, the most active isolate was identified using 16S rRNA sequencing.

Results: Marine Actinobacteria are one of the leading microbes of the ocean known for producing excellent secondary metabolites and having a broad spectrum of antimicrobial activity; hence, they are very important from an industrial point of view. The marine sediment sample used was collected from Kanyakumari beach, in the month of July, falling in the latitudinal range of $8.5074{ }^{\circ} \mathrm{N}$ and in the longitude of $76.9730^{\circ} \mathrm{E}$. A total of eight actinobacterial colonies were isolated by spread plate technique on Actinomycetes isolation agar, Kuster's agar, and starch casein agar. The isolate cultures were designated as UST1-UST8. Among them, UST3 showed a maximum zone of inhibition against clinical pathogens Salmonella typhi and Aspergillus niger with a zone of inhibition of $22 \mathrm{~mm}$ and $20 \mathrm{~mm}$, respectively. In solvent extraction study, ethyl acetate and hexane was found as best solvents for extraction. Potential isolate UST3 was identified as Streptomyces variabilis using morphological studies and 16S rRNA sequencing. Potential strain was submitted as $S$. variabilis-VITUMVB03.

Conclusion: Results obtained in this study concluded that marine Actinobacteria have broad-spectrum antimicrobial activity and can be used in the pharmaceutical industry.

Keywords: Antifungal activity, Antibacterial activity, Salmonella typhi, Aspergillus niger, Streptomyces variabilis.

(c) 2017 The Authors. Published by Innovare Academic Sciences Pvt Ltd. This is an open access article under the CC BY license (http://creativecommons. org/licenses/by/4. 0/) DOI: http://dx.doi.org/10.22159/ajpcr.2017.v10i9.19250

\section{INTRODUCTION}

More than $75 \%$ of our earth surface is covered with water, of which major parts comes under marine environment. Marine environment is already proven as a rich source for the production of bioactive compounds [1]. Among the bioactive compound producing organisms present in marine environments, Actinobacteria were found as the most potent group microorganisms producing a large variety of bioactive compounds such as antifungal, antibacterial, antioxidant, and antiviral agents [2]. Marine Actinobacteria are the most inventive producers of bioactive compounds. These highly active Actinobacteria have applications not only medical field but also have shown their potential in various other fields such as agriculture and various industries [3]. Actinobacteria are spore producing Gram-positive bacteria with high $\mathrm{G}+\mathrm{C}$ content in their DNA [4]. Marine Actinobacteria, when compare with terrestrial Actinobacteria are highly active, can produce different types of bioactive compounds and also have differences in their characteristics. These differences are due to the harsh marine environmental condition of marine Actinobacteria [5]. Most marine Actinobacteria of medical and economical applications comes under the subclass Actinobacteridae. In this subclass marine Streptomyces sp. are known as a source for the production of $60-70 \%$ of antibiotics. Most of the secondary metabolites that are used as antibacterial, antifungal, antiviral, antithrombotic, antitumor, and enzyme inhibitors are produced by Streptomyces sp. [6-8]. Furthermore, few available insecticides, herbicides, fungicides, and growth promoting substances for animals and plants are synthesized using marine Streptomyces.

After the discovery of penicillin and streptomycin antibiotics, many researchers felt the importance and need for the discovery of new drugs. Related to that importance various organisms were tested for their ability to produce antimicrobial compounds. Among all tested microorganisms marine Actinobacteria stood out as potential producers of many antimicrobial and antitumor compounds $[9,10]$. Antibacterial compounds produced from chemical means are very efficient in controlling many infections and diseases, but these bacterial pathogens are soon getting resistant to these drugs [11]. Therefore, at present, synthesis of naturally or biologically synthesized bioactive compounds are needed. In this case, marine Actinobacteria are seen as the most promising source. Most of these organisms show a broad spectrum activity, for example, bonactin drug isolated from Streptomyces sp. possess very good antifungal and antibacterial activity [12]. Similarly, marinomycin drug produced from Marinispora sp. have shown good antifungal and anticancer activities [13]. In the present world, fungal disease is on raise when compared with bacterial disease since fungal disease are difficult to treat due to the similarity in the mammalian and fungal cell structures [14]. Marine Actinobacteria are also viewed for its ability as a potential antifungal agent. Commercially available antifungal drugs such as neomycin, griseofulvin, and polyene antimycotics are used as applicants and cannot be taken orally. Hence for the production of oral drug with least side effects for fungal disease marine Actinobacteria has been tested [15]. Various conducted tests proved that marine Actinobacteria can be used as a useful biological tool for the production of antifungal drugs against pathogenic fungi [16]. Recently, antifungal activity of highly biocompatible form chitinase and its derivatives that are used in biomedical fields such as wound healing, cartilage tissue engineering, drug delivery, and nerve generation are synthesized by marine Actinobacteria [17-19]. N-(2-hydroxyphenyl)-2-phenazinamine is a new and active antibiotic isolated from Nocardia dassonvillei which showed significant antifungal activity against $C$. albicans $[19,20]$. Hence, this study was focused on antibacterial and antifungal activities of marine Actinobacteria isolated Kanyakumari marine sediments. 


\section{METHODS}

Chemicals and media

All the chemicals and media used in this study were purchased from HiMedia Laboratory Pvt. Ltd., Mumbai.

\section{Sample collection}

The marine sediments were collected from the Kanyakumari beach $\left(8.5074^{\circ} \mathrm{N}, 76.9730^{\circ} \mathrm{E}\right)$, Tamil Nadu, India. Samples were collected from at a depth of $10-15 \mathrm{~cm}$ from the topmost layer and aseptically transferred into sterile bags. All samples were then transferred to microbiology laboratory and stored at $4^{\circ} \mathrm{C}$ for further studies.

\section{Isolation of Actinobacteria}

Isolation of marine Actinobacteria from the collected sample was done using Actinomycetes isolation agar, starch casein agar, and Kuster's agar by spread plate technique by using $50 \%$ of marine water. All plates were supplemented with a small amount of nalidixic acid and potassium dichromate to avoid both bacterial and fungal contamination, respectively. All plates were then incubated at room temperature for 5-7 days. Plates were checked for powdery and leathery colonies followed by isolation, purification and storage at $4^{\circ} \mathrm{C}$ for further use [21].

\section{Clinical culture}

Bacterial pathogens and fungal pathogens such as Escherichia coli, Klebsiella pneumoniae, Staphylococcus aureus, Salmonella typhi, Aspergillus flavus, and Aspergillus niger were collected from Narayani Hospital, Sripuram, Vellore, Tamil Nadu.

\section{Fermentation media}

All eight isolates were separately inoculated in $100 \mathrm{ml}$ production media (soluble starch, glucose, yeast extract, trace elements, and distilled water) in a $250 \mathrm{ml}$ conical flask at $37^{\circ} \mathrm{C}$ in a shaker for 7 days at $120 \mathrm{rpm}$. After incubation period, all flasks were centrifuged at $1000 \mathrm{rpm}$ for 15 minutes and supernatant was collected to carry of bioactive activities.

\section{Antimicrobial activity \\ Antibacterial activity of actinobacterial isolates}

Agar well diffusion method was used to determine the antibacterial activity of the crude extract. Using a sterile gel borer $6 \mathrm{~mm}$ diameter of the well was made on agar media. Inoculums of clinical pathogens $(0.1 \mathrm{ml})$ were spread on the plates, and $100 \mu \mathrm{l}$ of crude extract $(20-200 \mu \mathrm{g} / \mathrm{ml})$ was loaded in different wells to evaluate their activity against clinical pathogens such as S. aureus, E. coli, S. typhi, and K. pneumoniae. Plates were incubated for $24 \mathrm{hrs}$ at $37^{\circ} \mathrm{C}$. After $24 \mathrm{hrs}$, plates were checked for zone of inhibition $[22,23]$.

\section{Antifungal activity of actinobacterial isolates}

Actinobacterial isolate UST-3 was inoculated in production media and incubated for 5 days at $28^{\circ} \mathrm{C}$. After incubation, the cultures were centrifuged at 10,000 rpm for 15 minutes, and the supernatant was collected for extract production. Inoculums of fungal pathogens $(0.1 \mathrm{ml})$ were spread on the plates, and $100 \mu \mathrm{l}$ of crude extract $(20-200 \mu \mathrm{g} / \mathrm{ml})$ was loaded in different wells to evaluate the antifungal activity against A. niger and A. flavus. Plates were incubated for $24 \mathrm{hrs}$ at $37^{\circ} \mathrm{C}$. After $24 \mathrm{hrs}$, plates were checked for zone of inhibition [21].

\section{Solvent extraction}

Solvent extract of the bioactive compound was done using four different solvent such as butanol, ethyl acetate, hexane, and chloroform. The potential actinobacterial isolate UST-3 was inoculated in production media and incubated at $37^{\circ} \mathrm{C}$ for 7 days. After incubation period, the broth was centrifuged at $1000 \mathrm{rpm}$ for 15 minutes and supernatant was collected. To the collected supernatant, equal volume of various solvent was added separately and kept in a rotary shaker for $24 \mathrm{hrs}$ to extract the active compound. The extracted compound from each solvent was then tested for their activity against $S$. typhi and A. niger by agar well diffusion method. After incubation, the zone of inhibition was measured [24].

\section{Identification of potential marine actinobacterial strains}

Identification of the potential isolates showing good antimicrobial and antioxidant activity was done using the key of Nonomura [25] and methods of Shirling and Gottlieb [26]. Along with this species level identification was also confirmed using cell wall composition analysis and by micromorphological studies $[27,28]$. Finally, the complete identification was done using molecular characterization based on 16S rRNA sequencing (Yaazh Xenomics, Chennai, Tamil Nadu, India). Bacterial genomic DNA was isolated using the InstaGeneTM Matrix Genomic DNA isolation Kit. The fragments were amplified bi-directionally using the forward (5'-AGAGTTTGATCMTGGCTCAG-3') and reverse (5'-TACGGYTACCTTGTTACGACTT-3') primers (MJ Research Peltier Thermal Cycler). The sequence was analyzed by ABI 3730xl capillary DNA sequencer (ABI Prism 310 Genetic Analyzer, Tokyo, Japan). Finally, the sequence was observed for similarity using NCBI BLAST similarity tool.

\section{Statistical analysis}

Using two-way analysis of variance values were analyzed between groups of same or different dpi. All values are shown as the mean \pm standard deviation. The significance of the differences between the mean values was determined using Student's t-test. For all statistical analysis, ${ }^{*} \mathrm{p}<0.05$ were considered significant.

\section{RESULTS AND DISCUSSION}

\section{Isolation of marine Actinobacteria}

Isolation of marine Actinobacteria was done on actinobacterial isolation agar, starch casein agar, and Kuster's agar. The result obtained in this study reveals that the salt pan sediment samples are rich in actinobacterial population. From the collected samples, a total of eight actinobacterial colonies were isolated (Fig. 1). Considering the total number of isolates, the maximum number were isolated on actinobacterial isolation agar (4), followed by starch casein agar (2) and Kuster's agar (2). The isolates were identified using culture characteristics as mentioned in ISP manual. All eight isolates were belonging to the genera Streptomyces sp. In a previous study, eight actinobacterial colonies were isolated on Actinomycetes isolation agar from Andaman and Nicobar Islands sediment samples [29]. A total of 21 actinobacterial colonies were isolated on Actinomycetes isolation agar from the marine sediments isolated from Mahabalipuram sea shore [30]. In our study, also out of eight actinobacterial colonies four were isolated on Actinomycetes isolation agar followed by starch casein agar and Kuster's agar.

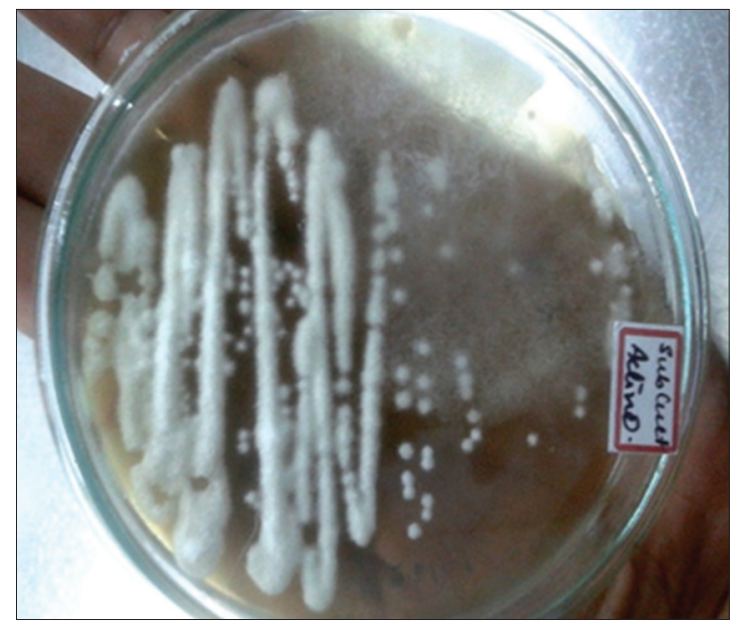

Fig. 1: Potential Actinobacterial isolated from Kanyakumari marine sediments 
Antibacterial activity of actinobacterial extract

The bioactive potential of all eight isolates was evaluated by testing their antibacterial potential against Gram-positive and Gram-negative bacteria. Among eight only one isolate UST-3 showed antimicrobial activity against all test pathogens. Cell-free supernatant of UST-3 showed maximum inhibition against $S$. typhi with a zone of inhibition of $22 \mathrm{~mm}$, followed by K. pneumoniae (16 mm) and E. coli $(14 \mathrm{~mm})$. The antibacterial profile shown by isolate UST-3 is shown in Fig. 2. The extract showed maximum activity at a dose of $200 \mu \mathrm{g} / \mathrm{ml}$ against all test pathogens. In a previous report marine Streptomyces sp. isolated from Royapuram, Muttukadu and Mahabalipuram sea shore showed activity $<13 \mathrm{~mm}$ against many clinical bacterial pathogens [30]. In another study marine Streptomyces sp. isolated from the southeast coast of India, Ramanathapuram, Sethu Karai, showed every good activity against clinical pathogens such as S. aureus, S. typhi and E. coli with a zone of inhibition above $20 \mathrm{~mm}$. Maximum activity was shown against $S$. typhi with an inhibition zone of $27 \mathrm{~mm}$ [31]. Hence, our study is in accordance with the previous reports, and also UST-3 showed similar and better results when compared with the available reports.

\section{Antifungal activity of actinobacterial extract}

Isolate UST-3 showed good antifungal activity against A. niger and A. flavus. Cell-free supernatant of UST-3 showed a maximum zone of inhibition (20 mm) against A. niger at a dose of $100 \mu \mathrm{g} / \mathrm{ml}$ followed by $15 \mathrm{~mm}$ of inhibition at a dose of $80 \mu \mathrm{g} / \mathrm{ml}$. Similarly, UST-3 showed maximum activity against $A$. flavus (14 mm) at a dose of $100 \mu \mathrm{g} / \mathrm{ml}$ followed by $80 \mu \mathrm{g} / \mathrm{ml}$ with a zone of inhibition of $6 \mathrm{~mm}$ (Fig. 3). In a previous study marine Streptomyces sp. isolated from marine sediments of Ennore, Chennai, Tamil Nadu, showed antifungal activity against A. niger and A. flavus with a zone of inhibition of $25 \mathrm{~mm}$ and $10 \mathrm{~mm}$,

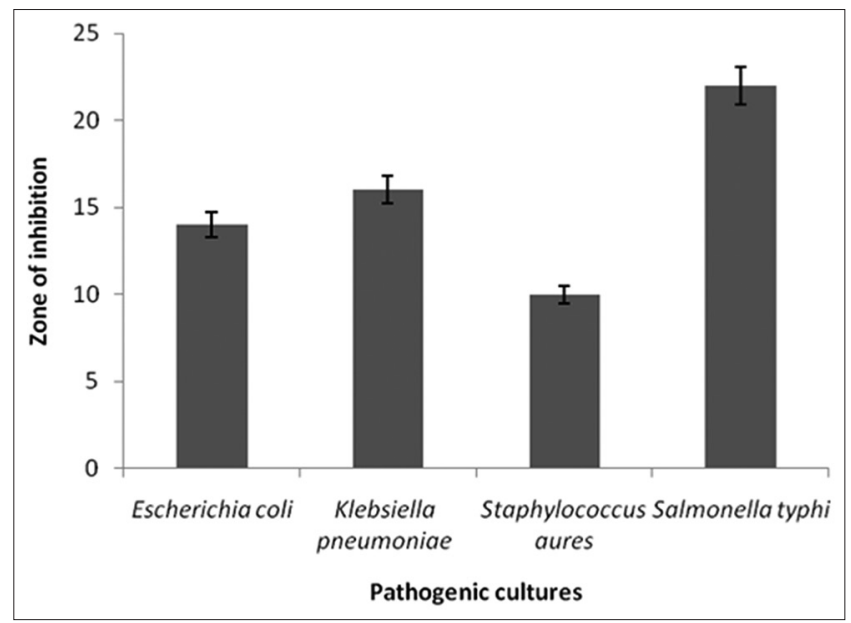

Fig. 2: Antibacterial activity of potential isolate UST-3 against clinical pathogens at $200 \mu \mathrm{g} / \mathrm{ml}$ dose

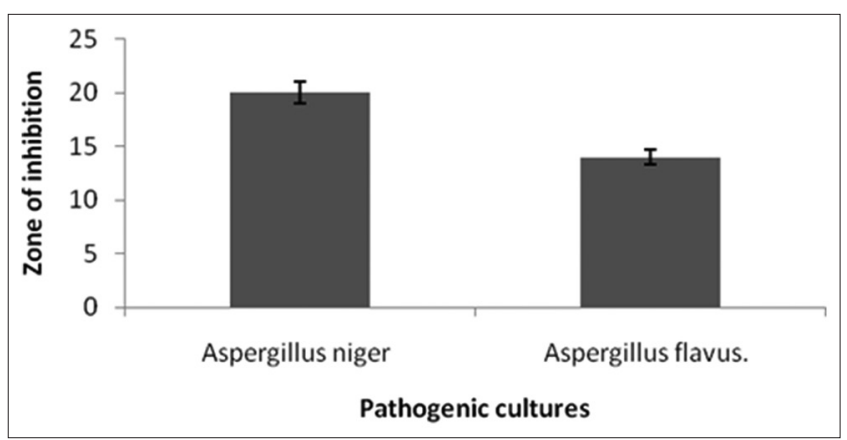

Fig. 3: Antifungal activity of potential isolate UST-3 against clinical pathogens at $100 \mu \mathrm{g} / \mathrm{ml}$ dose respectively [32]. Similarly, in another study antifungal activity of against $A$. niger with a zone of inhibition of $19 \mathrm{~mm}$ was reported using the crude extract of Streptomyces variabilis isolated from Thottada marine sediments, Kannur, Kerala [33]. In our study, also active isolate UST-3 showed the best activity against $A$. niger.

\section{Screening using solvent extracted compound}

In primary screening potential marine actinobacterial isolates UST-3 was selected for further studies, i.e., solvent extraction method. The isolate UST-3 showed a maximum zone of inhibition (27 $\mathrm{mm}$ ) using ethyl acetate as solvent against the test organism $S$. typhi (Fig. 4). Similarly, UST-3 showed a maximum zone of inhibition ( $22 \mathrm{~mm})$ using hexane as solvent against the test organism A. niger (Fig. 5). Here in this study, ethyl acetate and hexane was found as the best solvent for extraction of antibacterial and antifungal compounds from marine Actinobacteria. Ethyl acetate was reported as a suitable solvent for extraction of bioactive compounds from marine Actinobacteria [34], but in our study along with ethyl acetate, hexane also showed good active compound extraction ability.

\section{Identification of potential isolate UST-3}

Using 16S rRNA sequencing the potential isolate was identified as S. variabilis. The primary identification of potential strains done using the key of Nonomura, micromorphological studies and cell wall composition analysis also showed similar results (Table 1). Isolate UST-3 formed an extensively branched substrate mycelium which carried a recti flexible and smooth surface (Figs. 6 and 7). Potential isolate showed $99 \%$ of similarity with $S$. variabilis in the blast search analysis. The $16 \mathrm{~S}$ rRNA sequencing of potential strains was confirmed that it occupies a distinctive phylogenetic position with the radiation, including representatives of the family using neighbor-joining tree. Potential strain was submitted in NCBI as $S$. variabilis-VITUMVB03.

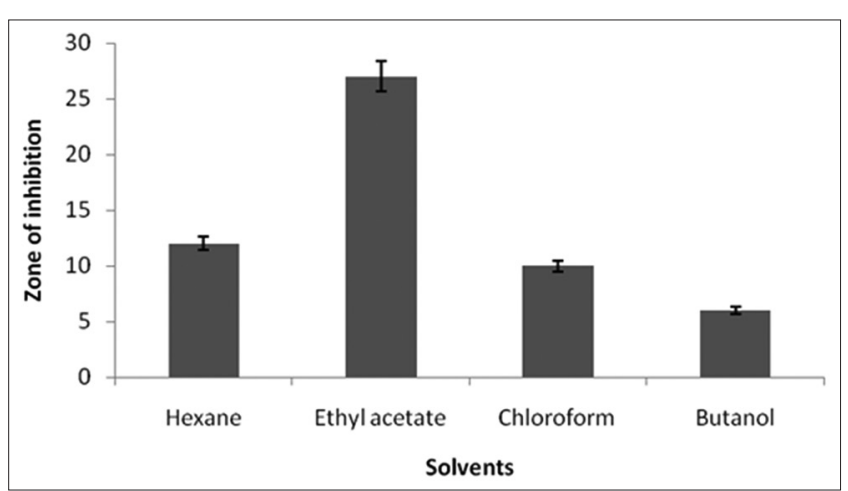

Fig. 4: Antibacterial activity of potential isolate UST-3 against Salmonella typhi using different solvents

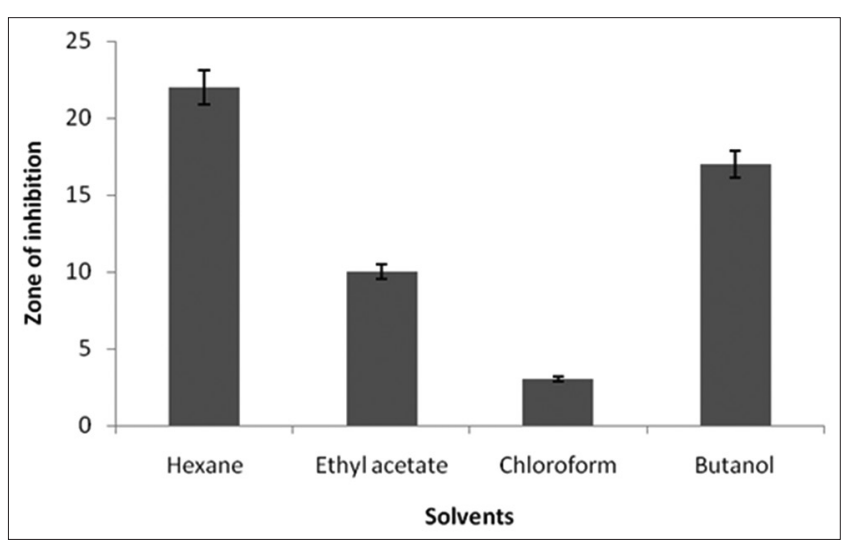

Fig. 5: Antifungal activity of potential isolate UST-3 against Aspergillus niger using different solvents 


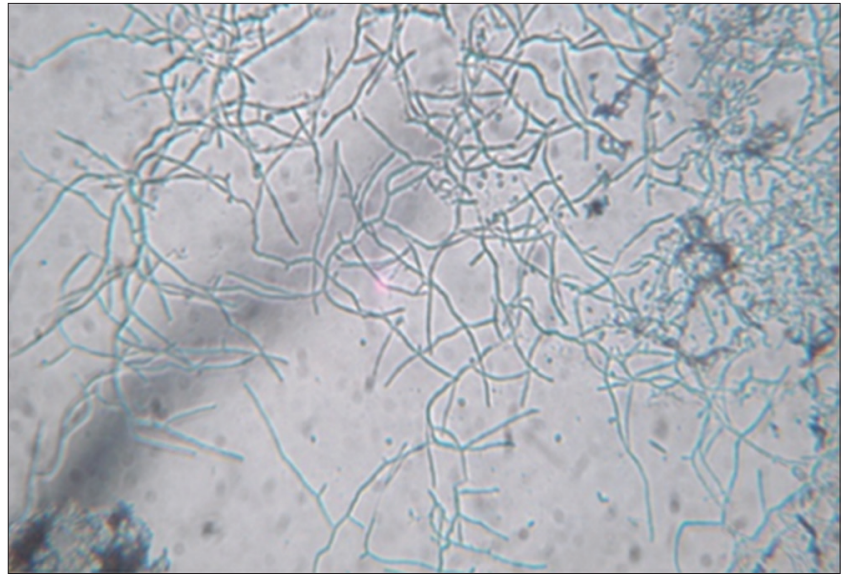

Fig. 6: Spore chain morphology of potential isolate UST-3

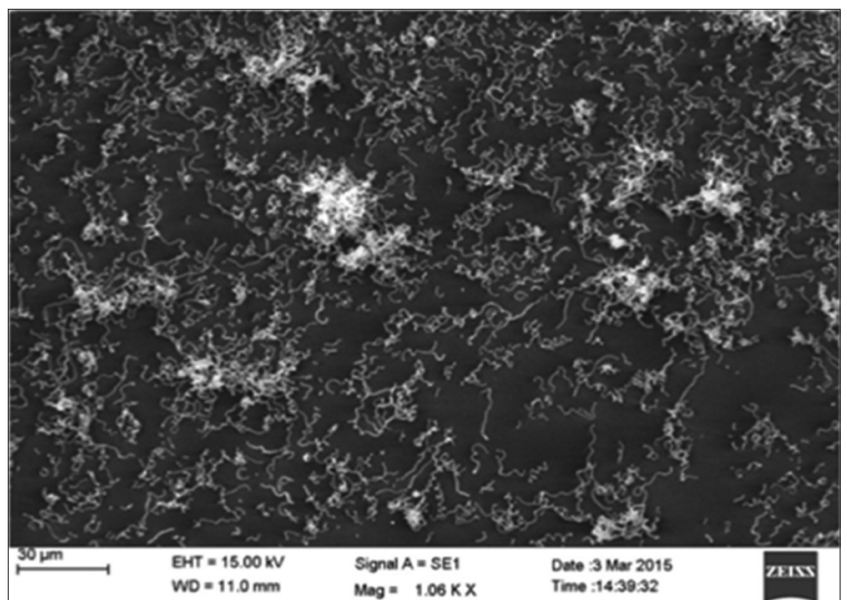

Fig. 7: Scanning electron microscopic image of potential isolate UST-3

Table 1: Morphological characteristic of UST-3

\begin{tabular}{ll}
\hline Characteristic & UST3 \\
\hline Gram staining & Off-grey \\
Color of aerial mycelium & - \\
Melanoid pigment & + \\
Reverse side pigment & - \\
Soluble pigment & - \\
Acid fast staining & - \\
Spore chain morphology & Recti fexible \\
\hline
\end{tabular}

\section{CONCLUSION}

Marine Actinobacteria are known producers of secondary metabolites; they are more miscellaneous and unique with this ability. The potential marine actinobacteria isolated in this study showed very good antibacterial and antifungal activities at a dose of $200 \mu \mathrm{g} / \mathrm{ml}$ and $100 \mu \mathrm{g} / \mathrm{ml}$, respectively. Potential isolate $S$. variabilis isolated from Kanyakumari marine sediments can be used as a promising source for the development of antibacterial and antifungal drugs.

\section{ACKNOWLEDGMENTS}

Authors are thankful to the management of VIT University for providing necessary facilities to carry out this study and also DST-FIST for providing SEM facilities.

\section{REFERENCES}

1. Zhang L, An R, Wang J, Sun N, Zhang S, Hu J, et al. Exploring novel bioactive compounds from marine microbes. Curr Opin Microbiol 2005;8(3):276-81

2. Wohlleben W, Mast Y, Muth G, Röttgen M, Stegmann E, Weber T. Synthetic biology of secondary metabolite biosynthesis in Actinomycetes: Engineering precursor supply as a way to optimize antibiotic production. FEBS Lett 2012;586(15):2171-6.

3. Mahajan GB, Balachandran L. Antibacterial agents from Actinomycetes - A review. Front Biosci (Elite Ed) 2012;4:240-53.

4. Ventura M, Canchaya C, Tauch A, Chandra G, Fitzgerald GF, Chater KF, et al. Genomics of Actinobacteria: Tracing the evolutionary history of an ancient phylum. Microbiol Mol Biol Rev 2007;71(3):495-548.

5. Rani KP, Doss A. Purification and antibacterial activity of marine Actinomycetes against human and fish pathogens. J Mar Sci Res Dev 2016;6(6):1-4.

6. Gupte M, Kulkarni P, Ganguli BN. Antifungal antibiotics. Appl Microbiol Biotechnol 2002;58(5):46-57.

7. Bressan W. Biological control of maize seed pathogenic fungi by use of Actinomycetes. Biocontrol 2003;48(2):233-40.

8. Atta MA, Ahmad MS. In-vitro antimicrobila activity of marine actinobacterial. Aust J Basic Appl Sci 2009;2(10):126-35.

9. Ghai R, McMahon KD, Rodriguez-Valera F. Breaking a paradigm: Cosmopolitan and abundant freshwater Actinobacteria are low GC. Environ Microbiol Rep 2012;4(1):29-35.

10. Miyadoh S. Research on antibiotic screening in Japan over the Last Decade. A producing microorganism approach. Actinomycetologia 1993;7(1):100-6.

11. Manivasagan P, Venkatesan J, Se-Kwon K. Introduction to marine Actinobacteria. Mar Microbiol 2013;1:1-19.

12. Stewart PS, Costerton JW. Antibiotic resistance of bacteria in biofilms. Lancet 2001;358(9276):135-8

13. Cohen SN, Chang AC, Hsu L. Non-chromosomal antibiotic resistance in bacteria: Genetic transformation of Escherichia coli by R-factor DNA. Proc Natl Acad Sci U S A 1972;69(8):2110-4.

14. Takahashi Y, Omura S. Isolation of new actinomycete strains for the screening of new bioactive compounds. J Gen Appl Microbiol 2003;49(3):141-54.

15. Hames-Kocabas EE, Uzel A. Isolation strategies of marine-derived Actinomycetes from sponge and sediment samples. J Microbiol Methods 2012;88(3):342-7.

16. Panchanathan M, Jayachandran V, Kannan S, Se-Kwon K. Pharmaceutically active secondary metabolites of marine actinobacterial. Microbiol Res 2014;169(4):262-78.

17. Bull AT, Stach JE. Marine Actinobacteria: New opportunities for natural product search and discovery. Trends Microbiol 2007;15(11):491-9.

18. Bhatnagar I, Kim SK. Pharmacologically prospective antibiotic agents and their sources: A marine microbial perspective. Environ Toxicol Pharmacol 2012;34(3):631-43.

19. Lazzarini A, Cavaletti L, Toppo G, Marinelli F. Rare genera of Actinomycetes as potential producers of new antibiotics. Antonie Van Leeuwenhoek 2000;78(3-4):399-405.

20. Hong K, Gao AH, Xie QY, Gao H, Zhuang L, Lin HP, et al. Actinomycetes for marine drug discovery isolated from mangrove soils and plants in China. Mar Drugs 2009;7(1):24-44.

21. Karthik L, Gaurav K, Rao KV. Diversity of marine Actinomycetes from nicobar marine sediments and its antifungal activity. Pharmacology 2010;2(1):221-7.

22. Saswati R, Choudhury MD, Paul SB. In vitro antibacterial activity of Alocasia decipiens Schott. Int J Pharm Pharm Sci 2013;5:155-7.

23. Packia LN, Vivek AS, Anusha S, Jeeva S, Raja BJ, Selva BM. Antibacterial activity of fresh water crab and snail and isolation of antibacterial peptides from haemolymph by SDS page. Int J Pharm Pharm Sci 2015;7(1):109-14.

24. Veena S, Swetha D, Karthik L, Rao KV. Assessment of anti-typhoid and antioxidant activity of marine Actinobacteria isolated from Chennai marine sediments. Der Pharm Lett 2016;8(3):166-72.

25. Nonomura $\mathrm{H}$. Key for classification and identification of 458 species of the streptomycetes included in ISP. J Ferment Technol 1974;58:78-92.

26. Shirling EB, Gottlieb D. Methods for characterization of Streptomyces species. Int J Syst Bacteriol 1966;16(3):313-40.

27. Lechevalier MP, Lechevalier H. Chemical composition as a criterion in the classification of aerobic Actinomycetes. Int J Syst Bacteriol 1970;20(4):435-43. 
28. Midhun KG, Girijasankar G. Isolation, screening and characterization of antibiotic producing Actinomycetes from Kapuluppada plastic waste dumping yard, Visakhapatnam. Int $\mathrm{J}$ Pharm Pharm Sci 2016;8(11):221-9.

29. Abirami M, Gopiesh KK, Kannabiran K. Antibacterial activity of marine Streptomyces sp. Isolated from Andaman \& Nicobar Islands, India. Int J Pharm Bio Sci 2013;4(3):280-6.

30. Valli S, Suvathi SS, Aysha OS, Nirmala P, Vinoth KP, Reena A. Antimicrobial potential of Actinomycetes species isolated from marine environment. Asian Pac J Trop Biomed 2012;2(6):469-73.

31. Jemimah NS, Subathra D, Mohanasrinivasan V, Shnavi BV. Antimicrobial, antioxidant and cytotoxic activity of marine
Streptomyces parvulus VITJS11 crude extract. Braz Arch Biol Technol 2015;58(2):198-207.

32. Lakshmipathy D, Kannabiran K. Isolation and characterization of antagonistic Actinomycetes from marine soil. J Micro Biochem Technol 2010;2:1-6.

33. Rao KV, Mandal S, Divya D, Sreedharan V. Bioactive potential of Streptomyces variabilis - Dv-35 isolated from Thottada marine sediments, Kannur, Kerala. Asian J Pharm Clin Res 2016;9(3):67-71.

34. Ogunmwonyi IH, Ntsikelelo M, Lenord M, Elivs N. In-vitro timekill studies of antibacterial agents from putative marine Streptomyces species isolated from the Nahoon Beach, South Africa. African J of Microbiol Res 2010;4(12):2223-30. 